\title{
A EDUCAÇÃO COMO UM DIREITO FUNDAMENTAL DE NATUREZA SOCIAL'
}

\author{
Clarice Seixas Duarte ${ }^{* *}$
}

\begin{abstract}
RESUMO: Parece haver consenso em torno da idéia de que a educação deve ser tratada como uma prioridade por nossos governantes. Contudo, a realidade demonstra que a educação escolar de qualidade ainda é um sonho distante, sobretudo para os setores mais vulneráveis de nossa sociedade. Poucos sabem quais as implicações práticas da enunciação, em nossa Constituição, do direito à educação como um direito fundamental de natureza social e, conseqüentemente, o que pode ser exigido do Estado para a sua satisfação. Quem são os titulares desse direito? Ele pode ser exigido coletivamente? Abrange apenas uma vaga no ensino fundamental ou o direito à realização de uma política pública? Há mecanismos jurídicos que podem ser acionados em caso de sua oferta irregular ou insuficiente? $O$ desafio desse artigo é delinear o regime jurídico de proteção do direito à educação como um direito fundamental de natureza social, buscando, com isso, contribuir para a ampliação das possibilidades concretas de sua realização.
\end{abstract}

Palavras-chave: Educação. Políticas públicas. Direitos sociais.

\section{EDUCATION AS A FUNDAMENTAL RIGHT OF SOCIAL NATURE}

ABSTRACT: There seems to be a consensus on the idea that our government should consider education as a priority. However, reality shows that education is still a distant dream, especially for the most vulnerable groups in our society. Both the practical implica-

* Parte destas idéias foi desenvolvida em minha tese de doutorado, $O$ direito público subjetivo ao ensino fundamental na Constituição Federal de 1988, apresentada ao Departamento de Filosofia e Teoria Geral do Direito da Universidade de São Paulo (USP).

** Doutora em Filosofia e Teoria Geral do Direito e professora do Programa de Mestrado em Direito Ambiental da Universidade do Estado do Amazonas (UEM).E-mail: clasduarte@uol.com.br

Educ. Soc., Campinas, vol. 28, n. 100 - Especial, p. 691-713, out. 2007 
tions of the fact that our Constitution states the right to education as a fundamental right of social nature and the requirements that can be addressed to the State to meet it are little known. Who is benefited by such right? May it be demanded collectively? Does it only mean a seat in an elementary school or the right to require public policies? May legal mechanisms be used in case of irregular or inadequate offer? The challenge of this article is to define the legal regime of the right to education as a fundamental right of social nature to contribute to increase the concrete possibilities for its satisfaction.

Key words: Education. Public policies. Social rights.

\section{Objeto de estudo}

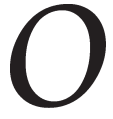

direito à educação, previsto no artigo $6^{\circ}$ da Constituição Federal de 1988 como um direito fundamental de natureza social, vem detalhado no Título VIII, Da Ordem Social, especialmente nos artigos 205 a 214, dispositivos nos quais se encontra explicitada uma série de aspectos que envolvem a concretização desse direito, tais como os princípios e objetivos que o informam, os deveres de cada ente da Federação (União, Estados, Distrito Federal e Municípios) para com a garantia desse direito, a estrutura educacional brasileira (dividida em diversos níveis e modalidades de ensino), além da previsão de um sistema próprio de financiamento, que conta com a vinculação ${ }^{1}$ constitucional de receitas. Trata-se de parâmetros que devem pautar a atuação do legislador e do administrador público, além de critérios que o Judiciário deve adotar quando chamado a julgar questóes que envolvam a implementação deste direito.

Além da previsão constitucional, há uma série de outros documentos jurídicos que contêm dispositivos relevantes a respeito do direito à educação, tais como o Pacto Internacional sobre os Direitos Econômicos, Sociais e Culturais, de 1966, ratificado pelo Brasil, no livre gozo de sua soberania, a 12 de dezembro de 1991, e promulgado pelo Decreto Legislativo n. 592, a 6 de dezembro de 1992; a Lei de Diretrizes e Bases da Educação Nacional (Lei n. 9.394/96), o Estatuto da Criança e do Adolescente (Lei n. 8.069/90), o Plano Nacional de Educação (Lei n. 10.172/2001), entre outros.

Não obstante a expressa previsão do direito à educação em diversos documentos jurídicos, ainda há muita polêmica quando se trata: 
a) da compreensão de sua verdadeira natureza jurídica (são verdadeiros direitos ou meros programas de ação, sem caráter vinculante para os poderes públicos?); b) da determinação de seus titulares (são apenas os indivíduos singularmente considerados ou também grupos e coletividades indeterminadas de pessoas?); c) do delineamento de seu objeto (abrange apenas uma vaga no ensino fundamental ou o direito à realização de políticas públicas?). Em síntese, o que se procura investigar neste artigo são as implicações do reconhecimento do direito à educação como um direito fundamental de caráter social e, conseqüentemente, o tipo de prestações exigíveis do poder público para a sua satisfação em caso de sua oferta irregular ou insuficiente.

Vale esclarecer que não será objeto deste estudo a análise a respeito das diversas formas de regulamentação do direito à educação em nosso ordenamento jurídico, mas, tão somente, a reflexão acerca do regime jurídico conferido à educação como um direito fundamental de natureza social. Para tanto, é necessário compreender o papel de destaque que foi conferido aos direitos fundamentais em nosso ordenamento jurídico, fruto do modelo de Estado adotado em nossa Constituição.

O Estado social e democrático de direito e o papel de destaque conferido aos direitos fundamentais de caráter social em nosso ordenamento jurídico

O Brasil constitui um Estado social de direito de inspiração democrática por imposição constitucional. Isto significa que os postulados subjacentes ao modelo de Estado social e ao regime político democrático não podem ser deixados de lado para compreensão e interpretação da ordem jurídica vigente. Tais princípios se fazem presentes já no caput do artigo $1^{\circ}$, que institui o Estado democrático de direito - tendo como fundamento a cidadania (inciso III) e o pluralismo político (inciso V). Já o parágrafo único do mesmo dispositivo consagra o princípio da soberania popular.

O caráter social deste Estado democrático de direito fica explícito no inciso III do artigo $1^{\circ}$, que incorpora a dignidade da pessoa humana como seu fundamento. Já o artigo $3^{\circ}$ estabelece, como objetivos fundamentais da República, a busca por uma sociedade livre, justa e solidária (inciso I) e a redução das desigualdades sociais (inciso 
III), este último também referido como princípio da ordem econômica (art. 170, VII).

O acolhimento dos princípios de um Estado social e democrático de direito pela Constituição brasileira impõe, para a concretização desse modelo, não apenas o respeito aos direitos individuais (liberdade de expressão, direito de voto, direito de ir e vir), como também a realização dos direitos sociais, de que são exemplos o direito à educação, ${ }^{2}$ ao trabalho, à saúde, entre outros. $\mathrm{O}$ papel de destaque conferido aos direitos fundamentais como um todo em nosso sistema desautoriza qualquer tentativa de negar ou esvaziar a natureza jurídica dos direitos sociais, como se estes não fossem verdadeiros direitos, mas meros conselhos ou exortações ao legislador. Tal esvaziamento, ademais, obstaria, ainda, a concretização dos objetivos de justiça social, explicitamente enunciados no artigo $3^{\circ}$ (especialmente incisos I e III).

Assim, como decorrência da adoção do modelo de Estado social, impõe-se aos poderes públicos uma série de tarefas tendentes à realização de finalidades coletivas - as quais não se limitam à produção de leis ou normas gerais (como ocorre no Estado de direito liberal); tampouco à garantia de participação popular no processo de tomada de decisões (exigência do Estado democrático de direito). No Estado social de direito, é a elaboração e a implementação de políticas públicas - objeto, por excelência, dos direitos sociais - que constituem o grande eixo orientador da atividade estatal, o que pressupõe a reorganização dos poderes em torno da função planejadora, tendo em vista a coordenação de suas funções para a criação de sistemas públicos de saúde, educação, previdência social etc.

A adoção dos princípios, objetivos e fundamentos do Estado social e democrático de direito fez com que a Constituição Federal de 1988 não se limitasse à fixação dos contornos do poder frente à liberdade do indivíduo, nem à organização das formas de participação popular na esfera das decisóes políticas. No âmbito desse Estado, de caráter prestacional, a positivação jurídica de valores sociais passou a servir de base não apenas à interpretação de toda a Constituição, mas à criação, direção e regulação de situações concretas. Neste contexto, as leis, no seu sentido de normas abstratas gerais, deixam de ser $o$ instrumento por excelência do Estado, uma vez que a promoção de seus objetivos sociais e a realização do princípio democrático, em sua materialidade, demandam intervenções por meio de políticas públicas (Comparato, 1997, p. 350). 
Não foi por acaso que a opção pelo Estado social e democrático de direito veio acompanhada de uma série de avanços no campo dos direitos fundamentais. Pela primeira vez na história constitucional do país, a matéria foi tratada com o devido destaque, passando a contar com um regime jurídico diferenciado.

O documento, produzido no bojo do processo de redemocratização do país, após um longo período da ditadura militar, tem como nota característica um forte viés dirigente, que atribui ao Estado papel essencial na efetivação dos direitos fundamentais de natureza social nele elencados.

Os artigos $5^{\circ}, 6^{\circ}$ e $7^{\circ}$ demonstram a forte influência, na Carta de 1988, do Pacto Internacional de Proteção dos Direitos Civis e Políticos e do Pacto Internacional de Proteção dos Direitos Econômicos, Sociais e Culturais, ambos de 1966. Percebe-se, ainda, a influência de várias constituiçôes ocidentais, dentre as quais se destacam a Lei Fundamental da Alemanha, de 1949, a Constituição da República Portuguesa, de 1976, e a Constituição Espanhola, de 1978. Foi dada ênfase à proteção da criança, do adolescente, do idoso e dos índios, cujos direitos foram previstos em capítulos especiais.

Tal como nos documentos internacionais que serviram de inspiração à Constituição de 1988, deve ser ressaltada a relevância dos direitos fundamentais como um todo na ordem jurídica vigente, reconhecidos como valores supremos da ordem constitucional, fonte legitimadora e razão de ser do próprio sistema jurídico.

No que se refere especificamente ao tema das garantias dos direitos fundamentais (mecanismos existentes para a efetivação de direitos), a Constituição avançou, tendo previsto uma série de remédios jurídicos próprios para sua proteção, tais como a ação civil pública, o mandado de injunção, o mandado de segurança coletivo etc. Aqui, há que se destacar, especialmente, o papel conferido ao Ministério Público pela atual Carta Magna, que vem atuando intensamente na exigibilidade dos direitos sociais.

Deve-se mencionar, ainda, a inovação trazida pelo artigo $5^{\circ}, \mathbb{S}$ $1^{\circ}$, da Constituição Federal (CF), que atribui aplicabilidade imediata às normas definidoras de direitos e garantias fundamentais. Apesar da falta de consenso sobre o alcance desse dispositivo, ele, sem dúvida, aponta para um tratamento diferenciado e reforçado a ser dispensado a 
essa categoria de direitos, abalando a doutrina que atribuía o caráter de normas programáticas aos direitos sociais, como se elas fossem desprovidas de caráter verdadeiramente imperativo, ou seja, como se não fossem capazes de vincular a atuação dos poderes públicos.

Já o artigo $60, \$ 4$, da CF/88 estabelece o rol das chamadas "cláusulas pétreas", disposições constitucionais revestidas de proteção especial contra a ação do poder constituinte derivado. Isso significa que o legislador constituinte reservou um conjunto de matérias cuja relevância impede a sua supressão pelo legislador ordinário, criando limites materiais à reforma constitucional. Na realidade, elegeu-se um conjunto de direitos e garantias que não podem sequer ser objeto de proposta de emenda constitucional tendente à sua abolição. Contudo, a utilização da expressão "direitos e garantias individuais" no artigo $60, \$ 4^{\circ}$, inciso IV, da CF/ 88 , veio ensejar uma série de disputas doutrinárias acerca do verdadeiro alcance do dispositivo, discutindo-se se o mesmo seria aplicável aos direitos sociais ou apenas aos direitos civis e políticos.

No nosso entendimento, o artigo $60, \$ 4^{\circ}$, IV, apesar de conferir caráter de cláusula pétrea apenas aos "direitos e garantias individuais", em detrimento dos demais direitos fundamentais, deve ser interpretado de forma mais ampla, devendo abarcar os direitos sociais previstos em nossa Constituição. Tal posicionamento justifica-se pelo fato de os direitos sociais receberem, em nosso ordenamento,

(...) uma garantia tão elevada e reforçada que lhes faz legítima a inserção no mesmo âmbito conceitual da expressão direitos e garantias individuais do art. 60. Fruem, por conseguinte, uma intangibilidade que os coloca inteiramente além do alcance do poder constituinte ordinário, ou seja, aquele poder constituinte derivado, limitado e de segundo grau, contido no interior do próprio ordenamento jurídico. (Bonavides, 2000, p. 594-595)

Cumpre lembrar, ainda, que, além do catálogo de direitos sociais previstos expressamente na Constituição Federal de 1988 (especialmente no artigo $6^{\circ}$ ), os direitos econômicos, sociais e culturais decorrentes do regime (democrático) e dos princípios (do Estado social de direito, por exemplo), bem como aqueles expressos nos tratados e convençôes internacionais de proteção aos direitos humanos em que o Brasil seja parte, entre os quais se inclui o Pacto Internacional de Proteção aos Direitos Econômicos, Sociais e Culturais, de 1966, passam a integrar o 
ordenamento jurídico brasileiro. No caso dos tratados e convençôes sobre direitos humanos que forem aprovados, em cada casa do Congresso Nacional, em dois turnos, por três quintos dos votos dos respectivos membros, os mesmos serão equivalentes às emendas constitucionais, tendo em vista o disposto no artigo $5^{\circ}, \$ \$ 2^{\circ}$ e $3^{\circ} \mathrm{da} \mathrm{CF} / 88$.

Merece destaque especial, ainda, o preâmbulo da Constituição, onde estão enunciados, juntamente com os artigos $1^{\circ}$ e $3^{\circ}$, os princípios que delimitam a estrutura política, econômica e social sobre as quais os direitos fundamentais serão exercidos, bem como os valores básicos sobre os quais todo o ordenamento se assenta (liberdade, igualdade, dignidade humana etc.).

Todo este conjunto mostra o reforço que o sistema constitucional brasileiro dispensou aos direitos fundamentais como um todo e, particularmente, aos sociais, conferindo-lhes aplicabilidade imediata (art. $5^{\circ}, \mathbb{1} 1^{\circ}$ ), proteção contra a ação do legislador infraconstitucional (art. 60, $\$ 4^{\circ}$, inciso IV) e, no caso da incorporação dos tratados ou convenções de direitos humanos, conforme previsto no artigo $5^{\circ}$, $\$ \$$ $2^{\circ}$ e $3^{\circ}$, status de emenda constitucional.

Titularidade, objeto e alcance do direito à educação à luz da Constituição Federal de 1988 e do Pacto Internacional de Direitos Econômicos, Sociais e Culturais

$\mathrm{O}$ artigo $6^{\circ}$ da Constituição Federal de 1988 reconhece a educação como um direito fundamental de natureza social. Sua proteção tem, pois, uma dimensão que ultrapassa, e muito, a consideração de interesses meramente individuais. Assim, embora a educação, para aquele que a ela se submete, represente uma forma de inserção no mundo da cultura e mesmo um bem individual, para a sociedade que a concretiza, ela se caracteriza como um bem comum, já que representa a busca pela continuidade de um modo de vida que, deliberadamente, se escolhe preservar. Daí a afirmação:

(...) a educação não é uma propriedade individual, mas pertence por essência à comunidade. $\mathrm{O}$ caráter da comunidade imprime-se em cada um de seus membros e é no homem, muito mais do que nos animais, fonte de toda a ação e de todo comportamento. Em nenhuma parte o influxo da comunidade nos seus membros tem maior força que no 
esforço constante de educar, em conformidade com seu próprio sentir, cada nova geração. A estrutura de toda a sociedade assenta nas leis e normas escritas e não escritas que a unem e unem seus membros. (Jaeger, 1989, p. 4)

Ora, se a proteção de um bem jurídico como a educação envolve a consideração de interesses supra-individuais, deve-se reconhecer que a sua titularidade não recai apenas sobre indivíduos singularmente considerados, mas abrange até mesmo os interesses de grupos de pessoas indeterminadas ou de difícil determinação, como as futuras gerações, que têm direito ao acesso às tradiçôes públicas, preservadas e transmitidas pela ação educacional. Trata-se, pois, de um direito que, mesmo podendo ser exercido individualmente, não pode ser compreendido em abstração de sua dimensão coletiva e até mesmo difusa.

A Constituição Federal, em seu artigo 205, reconhece, explicitamente, a educação como um direito de todos, consagrando, assim, a sua universalidade. ${ }^{3}$ Trata-se de direitos que devem ser prestados sem preconceitos de origem, raça, sexo, cor, idade e quaisquer outras formas de discriminação (cf. art. 30, IV da CF/88). Contudo, não obstante o reconhecimento expresso da universalidade dessa categoria de direitos, a sua implementação demanda a escolha de alvos prioritários, ou seja, grupos de pessoas que se encontram em uma mesma posição de carência ou vulnerabilidade. ${ }^{4}$ Isso porque o objetivo dos direitos sociais é corrigir desigualdades próprias das sociedades de classe, aproximando grupos ou categorias marginalizadas.

Como conseqüência, tem-se que o poder público, titular do dever jurídico correlato ao direito à educação, conforme expressamente previsto no artigo 205 da CF/88, deverá organizar-se para fornecer os serviços educacionais a todos, de acordo com os princípios estatuídos na Constituição, sempre no sentido de ampliar cada vez mais as possibilidades de que todos venham a exercer igualmente este direito. Trata-se, aqui, do reconhecimento da progressividade desta categoria de direitos, expressa no Pacto Internacional dos Direitos Econômicos, Sociais e Culturais. O artigo $2^{\circ}$, alínea I, do referido documento estabelece que os direitos que têm por objeto programas de ação estatal seriam realizados progressivamente, até o máximo dos recursos disponíveis de cada Estado.

O problema é que a linguagem empregada neste dispositivo tem contribuído para a reprodução de teorias que reduzem o peso jurídico 
dos direitos sociais, cuja progressividade vem sendo sistematicamente utilizada como justificativa para postergar, para um futuro incerto, a realização dos direitos nele previstos, servindo como artifício para legitimar o não-cumprimento de obrigações impostas aos estados.

O Comentário Geral n. 3, de 1990, do Comitê de Direitos Econômicos, Sociais e Culturais da ONU, oferece uma interpretação oficial sobre a natureza das obrigaçóes impostas aos Estados-partes. De acordo com as Naçôes Unidas, o conceito de progressividade indica que a plena realização dos direitos econômicos, sociais e culturais, de modo geral, não poderá ser atingida em um curto período de tempo. Entretanto, para o Comitê, a progressividade não deve ser interpretada como uma forma de esvaziar a obrigação de conteúdo substantivo. Ela seria apenas uma forma de levar em conta a realidade do mundo concreto e as dificuldades envolvidas no que concerne à tarefa de assegurar a plena realização dos direitos econômicos, sociais e culturais.

Por outro lado, a expressão deve ser iluminada pelo objetivo geral ou razão de ser do Pacto, qual seja, o estabelecimento de obrigações claras para os Estados-partes, visando à plena realização dos direitos ali mencionados. De acordo com a própria ONU, portanto, o Pacto impóe, de fato, aos Estados, a obrigação de mover-se efetiva e prontamente em direção àquele objetivo. Além do mais, qualquer medida retroativa deliberada nessa direção requereria a mais cautelosa consideração e precisaria ser plenamente justificada (Comentário Geral n. 3, 1990, apud Steiner \& Alston, 1996, p. 283-285).

Ainda de acordo com o Comitê, enquanto o objetivo geral de plena realização dos direitos enunciados no Pacto só pode ser implementado em longo prazo, a progressividade impóe ao Estado o dever de tomar medidas concretas e delimitadas da forma mais clara possível em direção às obrigações assumidas (obrigaçóes de conduta e não de resultado, propriamente ditas), o que deve ser demonstrado em curto espaço de tempo, a partir da entrada do Pacto em vigor.

Esse seria um exemplo de obrigação de implementação imediata estabelecida pelo Pacto. Se o limite dos recursos disponíveis pode impedir a realização integral dos direitos, não é possível deixar de perseguilos, desde já, de acordo com os recursos disponíveis. É uma questão de estabelecer prioridades. Outra obrigação de implementação imediata é a garantia de que os direitos serão exercidos sem discriminação. 
O importante é ficar claro que a noção de progressividade dos direitos sociais não pode ser confundida com a possibilidade de sua não aplicação. De acordo com o que está previsto no próprio Pacto, cabe aos Estados adotar medidas até o máximo de seus recursos disponiveis (art. $2^{\circ}$ ), o que significa o dever de executar avanços concretos em prazos determinados. Assim, a progressividade cria um empecilho ao retrocesso da política social do Estado que, tendo alcançado um certo nível de proteção dos respectivos direitos, não pode retroceder e baixar o padrão de vida da comunidade, já que a cláusula de proibição do retrocesso social protege o núcleo essencial dos direitos sociais. O princípio da proibição de retrocesso social pode ser assim formulado:

(...) o núcleo essencial dos direitos sociais já realizado e efetivado através de medidas legislativas ("lei de segurança social", "lei do subsídio de desemprego", "lei do serviço de saúde") deve considerar-se constitucionalmente garantido, sendo inconstitucionais quaisquer medidas estaduais que, sem a criação de outros esquemas alternativos compensatórios, se traduzem na prática numa "anulação", "revogação" ou "aniquilação" pura e simples desse núcleo essencial. A liberdade de conformação do legislador e inerente auto-reversibilidade têm como limite o núcleo essencial já realizado. (Canotilho, 1999, p. 327)

A respeito da relação entre a noção de progressividade dos direitos sociais e o princípio da proibição do retrocesso social, Piovesan (2000, p. 177) observa:

(...) da obrigação da progressividade na implementação dos direitos econômicos, sociais e culturais decorre a chamada cláusula de proibição do retrocesso social, na medida em que é vedado aos Estados retrocederem no campo de implementação desses direitos. Vale dizer, a progressividade dos direitos econômicos, sociais e culturais proíbe o retrocesso ou a redução de políticas públicas voltadas à garantia desses direitos.

Se a concepção oficial e a doutrina vigente impedem que o conceito de progressividade seja interpretado como justificativa para não aplicação das disposições contidas no Pacto, os tribunais continuam sistematicamente ignorando a matéria. Via de regra, prevalece a discricionariedade dos Estados quanto ao momento de implementação de medidas concretas. Contudo, se os Estados não podem, de um dia para o outro, efetivar de forma integral e para todos os direitos previstos no Pacto, isso não significa que não devam agir de imediato, utilizando o máximo 
dos recursos disponíveis, e sempre em direção aos parâmetros internacionalmente estabelecidos, em evolução ascendente contínua. Não é possível retroagir. Esse é o sentido da progressividade.

Já o conceito de núcleo mínimo obrigatório (minimum core obligation) é importante para avaliar o comportamento estatal no cumprimento de suas obrigaçóes. Assim, diante de recursos escassos, o Estado deverá demonstrar que empenhou todos os esforços para utilizar os recursos disponíveis, tendo em vista, no mínimo, a satisfação daquilo que foi eleito como prioritário, ou seja, suas obrigações mínimas essenciais. No que diz respeito aos meios que deverão ser empregados pelos Estados, cumpre esclarecer que o rol estabelecido pelo artigo $2^{\circ}$, I, do Pacto, não é exaustivo. A adoção de medidas legislativas, prevista nesse dispositivo, não esgota as obrigaçōes do Pacto, devendo estenderse para medidas administrativas, financeiras, educacionais e sociais (Comentário Geral n. 3, 1990, apud Steiner \& Alston, 1996, p. 284).

Tomando-se o exemplo do direito à educação, previsto no artigo 13 do Pacto, tem-se que os

Estados-partes no presente Pacto reconhecem o direito de toda pessoa à educação. Concordam em que a educação deverá visar o pleno desenvolvimento da personalidade humana e do sentido de sua dignidade e a fortalecer o respeito pelos direitos humanos e liberdades fundamentais. Concordam, ainda, que a educação deverá capacitar todas as pessoas a participar efetivamente de uma sociedade livre, favorecer a compreensão, a tolerância e a amizade entre todas as naçôes e entre todos os grupos raciais, étnicos ou religiosos e promover as atividades das Naçôes Unidas em prol da manutenção da paz. (Inciso I)

No que diz respeito às obrigações postas aos Estados-partes pelo Pacto no campo educacional, o inciso II do artigo 13 estabelece que, para assegurar o pleno exercício desse direito: a) a educação primária deverá ser obrigatória e acessível gratuitamente a todos; b) a educação secundária em suas diferentes formas, inclusive a educação técnica e profissional, deverá ser generalizada e tornar-se acessível a todos, por todos os meios apropriados e, principalmente, pela implementação progressiva do ensino gratuito; c) a educação de nível superior deverá igualmente tornar-se acessível a todos, com base na capacidade de cada um, por todos os meios apropriados e, principalmente, pela implementação progressiva do ensino gratuito; d) a educação de base para os que não 
receberam educação primária ou não concluíram o ciclo completo de educação primária deverá ser intensificada na medida do possível; e) deve haver o desenvolvimento de uma rede escolar em todos os níveis de ensino, com um sistema adequado de bolsas de estudo e melhoria contínua das condiçôes materiais do corpo docente.

Finalmente, o artigo 14 estabelece que

(...) todo Estado-parte no presente Pacto que, no momento em que se tornar Parte, ainda não tenha garantido em seu próprio território ou território sob sua jurisdição a obrigatoriedade ou gratuidade da educação primária, se compromete a elaborar e adotar, dentro de um prazo de dois anos, um plano de ação detalhado destinado à implementação progressiva, dentro de um número razoável de anos estabelecido no próprio plano, do princípio da educação obrigatória e gratuita para todos.

No que se refere à natureza das obrigações estatais direcionadas à efetivação do direito à educação, vale destacar que os artigos 13 (II) e 14 do Pacto, combinados com o artigo $2^{\circ}$ (I) supra-referido, estabelecem obrigações de caráter prestacional a serem realizadas progressivamente ou, ainda, impõem ao Estado a adoção de medidas legislativas concretas para aprimorar a proteção desses direitos. Já o artigo 13, inciso II, do Pacto prevê outro tipo de obrigação estatal. Por meio desse dispositivo, os Estados-parte obrigam-se a respeitar a liberdade dos pais e, quando for o caso, dos tutores legais, de escolher para seus filhos escolas distintas daquelas criadas pelas autoridades públicas e de fazer com que seus filhos venham a receber educação religiosa ou moral de acordo com suas próprias convicções.

Trata-se, portanto, de estabelecer uma obrigação negativa para o Estado (não interferir na esfera individual), tal como ocorre com a proteção dos direitos de liberdade. Nesse caso, está sendo resguardada a liberdade dos pais escolherem o tipo de educação dos seus filhos. Isso mostra como o direito à educação pode abranger, concomitantemente, um aspecto social e outro liberal ou individual.

$\mathrm{O}$ aspecto social gera obrigaçóes estatais positivas tendentes a tornar o direito à educação primária disponível e acessível a todos, incluindo crianças de rua, comunidades rurais dispersas, portadores de necessidades especiais etc. Cabe aos Estados-partes a aplicação de investimentos para a organização e manutenção de um sistema público de educação capaz de garantir o acesso de todos a escolas públicas, 
sempre de acordo com o princípio da não-discriminação. Ressalte-se, ainda, que o Pacto impõe não apenas a responsabilidade de tornar a educação primária gratuita, como também compulsória. No que diz respeito aos objetivos educacionais, o Pacto retoma o espírito da Declaração Universal dos Direitos Humanos, de 1948 (especialmente art. 26, II), reforçando sua imperatividade.

Quanto à educação de nível superior, o Pacto estabelece que os Estados deverão igualmente torná-la acessível a todos, principalmente pela implementação progressiva do ensino gratuito. Ou seja, qualquer política que tenha como objetivo implementar o ensino remunerado em estabelecimentos oficiais representaria um retrocesso social, proibido pelo Pacto, já que o Estado deve ampliar progressivamente a oferta de vagas gratuitas e está vetado de retroceder nesse sentido.

Do que foi exposto a respeito do Pacto Internacional de Proteção dos Direitos Econômicos, Sociais e Culturais, é possível afirmar que a proteção desta categoria de direitos compete ao Estado como um todo, o qual deve criar condiçốes reais para o seu gozo. O Executivo, sujeito às obrigações assumidas no plano internacional, deve implementar as políticas públicas necessárias à concretização desses direitos. A vinculação aos documentos internacionais tampouco exime o Legislativo. No caso específico do direito à educação, é preciso fazer planos e destinar recursos financeiros à criação de condições de acesso e permanência no ensino, além de ampliar as possibilidades existentes. Já o Judiciário, por ser um poder inerte, que só atua mediante provocação, deverá julgar as disputas envolvendo a concretização desse direito, as quais terão, muitas vezes, no pólo passivo da relação jurídica instaurada, o próprio Executivo ou Legislativo. Uma coisa é certa: em caso da oferta irregular ou insuficiente das prestaçóes educacionais, tanto os parâmetros internos quanto os internacionais deverão ser utilizados. Vale mencionar que os parâmetros internacionais não constituem um teto, mas um mínimo razoável no tocante à proteção dos direitos humanos. Assim, deve prevalecer, no sistema interno, o que for mais avançado em termos de proteção.

Pois bem, após a análise do aparato internacional constante do Pacto, cumpre verificar como a Constituição Federal de 1988 se relaciona com os compromissos firmados internacionalmente. Ao estabelecer, em seu artigo 205, que a educação deve visar o pleno desenvolvimento da pessoa e seu preparo para o exercício da cidadania, a Constituição 
reproduz, expressamente, importantes obrigações internacionalmente assumidas a esse respeito (conforme disposto no art. 13, inciso I do Pacto). Entretanto, pode-se dizer que o Pacto representa um avanço em relação ao disposto na Constituição sobre a matéria, pois estabelece explicitamente que a educação deve visar o pleno desenvolvimento do sentido da dignidade humana, além do fortalecimento do respeito aos direitos humanos e às liberdades fundamentais, obrigações que, a partir da Constituição de 1988, passaram a integrar nosso ordenamento jurídico.

No que se refere ao objetivo de qualificação para o trabalho, também previsto no artigo 205 da nossa Carta, há que se refletir sobre a histórica polêmica a respeito da pertinência do estabelecimento de caráter profissionalizante do ensino médio, hoje também discutida em relação ao ensino fundamental. Bem fez o Pacto ao definir, como objetivo desses níveis de ensino, o fortalecimento do sentido da dignidade humana e o respeito aos direitos humanos, verdadeiros fundamentos do direito à educação.

Quanto ao estabelecimento da obrigatoriedade e gratuidade da educação primária (ensino fundamental, entre nós), a Constituição Federal avançou em relação ao Pacto; especialmente no que diz respeito à previsão expressa da possibilidade do particular constranger o Estado, judicialmente, a garantir o acesso ao ensino obrigatório e gratuito, contando, inclusive, com uma sanção expressa em caso de descumprimento (responsabilidade da autoridade competente, nos termos do $\$ 2^{\circ}$ do referido artigo). Entretanto, o Estado brasileiro deve cuidar para seguir as orientaçôes expressas do Pacto, tais como "prosseguir ativamente o desenvolvimento de uma rede escolar em todos os níveis". Não pode, portanto, por exemplo, reduzir o sistema de bolsas hoje ofertado e nem deixar de criar políticas públicas para "melhorar continuamente as condiçôes materiais do corpo docente" (conforme disposto no inciso II do art. 13).

Além dos princípios e fundamentos inscritos no Pacto Internacional e, no plano interno, nos artigos $1^{\circ}$ e $3^{\circ}$ da CF/88 supramencionados, e dos objetivos mencionados no artigo 205, deve-se citar, ainda, como diretrizes para a elaboração de políticas públicas educacionais e para a interpretação dos dispositivos relativos à matéria, os princípios consagrados no artigo 206 da Constituição Federal. Destacamos, aqui, a igualdade de condições para o acesso e permanência na escola (art. 206, inciso I), a gratuidade do ensino em estabelecimentos oficiais (art. 
206, inciso II), a valorização dos profissionais do ensino (art. 206, inciso v), a gestão democrática do ensino público (art. 206, inciso vI) e a garantia de padrão de qualidade (art. 206, inciso VII).

O princípio da igualdade de condiçôes para acesso e permanência na escola constitui uma diretriz fundamental que deve informar as políticas públicas educacionais. Em um país de imensas desigualdades sociais e regionais, torna-se imperativo aos poderes públicos a implementação de políticas públicas voltadas à redução das condições que levam a altos índices de abandono (evasão ou não permanência na escola), reprovação e distorção na relação idade-série. Só assim será possível garantir a permanência, o reingresso e o sucesso escolar de grupos que apresentam maior vulnerabilidade (Veras \& Martins, 2000, p. 402). Aí se incluem, por exemplo, as políticas públicas de combate ao trabalho infantil, o prolongamento do tempo de escolaridade e da jornada escolar, as atividades de recuperação, valorização do professor, implantação de um sistema de transporte escolar, material didático etc.

Já o princípio da gratuidade ${ }^{5}$ do ensino público em estabelecimentos oficiais está intimamente ligado ao problema da democratização do acesso à educação e constitui um direito, não uma concessão ou um favorecimento. Não se deve aceitar, portanto, a prática de cobrança de mensalidades na escola pública, que, aliás, seria discriminatória:

A prática de mensalidades e bolsas, corrente na empresa privada de ensino, é discriminatória na escola pública. Separa o aluno que pode e o aluno que não pode. Alunos "ricos" ou "remediados" ou "auto-suficientes" deverão pagar diretamente ao colégio ou à faculdade, a fim de que a administração venha a emprestar dinheiro a outros ditos "pobres" ou "dependentes". Desaparece, de plano, a mediação universal que é a figura do estudante de escola pública, cidadão igual aos colegas perante a lei. Essa mediação obtém-se, numa sociedade democrática, pelo bom uso de impostos gerais que todos os cidadãos se devem mutuamente, conforme os seus salários e as suas rendas. Os tributos devem ser geridos publicamente por um governo representativo, o qual aplicará - também publicamente - os seus recursos em áreas consideradas prioritárias para todos os cidadãos. Na verdade, a escola dita "gratuita", acessível a todos, baseia-se no pressuposto de que todos já estão pagando, proporcionalmente, via Estado, para o bem de todos e de cada um. Cada cidadão deve merecer a redistribuição constante e sistemática do bem público, principalmente em setores vitais que empenham a pessoa e a sociedade por um longo tempo. (Bosi, 1992, p. 217; grifos do autor). 
As reflexões de Bosi apontam para a importância do princípio da solidariedade em um Estado social e democrático de direito. A solidariedade diz respeito à relação de todas as partes de um todo entre si e perante o próprio todo, de tal forma que a relação de todos os cidadãos entre si, ou da sociedade com qualquer cidadão em particular, deve orientar-se segundo este princípio, sem o qual a sociedade tenderia para a atomização. Por meio dele, impõem-se deveres positivos de colaboração, levando-se em conta as diferenças de condição social. Este princípio, complemento necessário à afirmação das liberdades individuais e da igualdade perante a lei, está calcado na idéia de justiça distributiva, ou seja, na justiça que busca a compensação entre os que têm e os que não têm, entre os ricos e pobres, na distribuição de bens e serviços pelos poderes públicos.

Um exemplo de aplicação prática do critério da justiça distributiva é a submissão do sistema tributário ao princípio da capacidade contributiva de cada um, atribuindo-se as prestações públicas de bens e serviços aos cidadãos, de acordo com suas necessidades. A distribuição desses bens deve ser feita pelo Estado, responsável pela organização dos sistemas públicos que dão concretude aos direitos sociais, levando-se em conta as diferenças biológicas e culturais entre os grupos de seres humanos, de tal forma que ela se dê de modo proporcional. Assim, o acesso à educação de uma pessoa portadora de necessidades especiais envolve gastos mais elevados do que aqueles resultantes da mera divisão aritmética do total dos valores disponíveis pelo número de educandos de um determinado município, por exemplo. ${ }^{6}$

Já o princípio da garantia de padrão de qualidade, previsto no artigo 206, inciso VII da Constituição, é explicitado no artigo $4^{\circ}$, IX, da Lei de Diretrizes e Bases da Educação Nacional, dispositivo que define referenciais mínimos de qualidade de ensino. Existem alguns parâmetros objetivos que servem como orientação nesta matéria, tais como o grau de formação dos professores, a disponibilidade de material didático e de apoio, a adequação de currículos à realidade local, a implantação de sistemas de avaliação, sem falar na melhoria da remuneração e condições de trabalho dos professores, entre outros.

Do que foi exposto, é possível afirmar que a necessidade de criação de oportunidades concretas que garantam, na prática, condições de fruição do direito à educação aos grupos mais vulneráveis é, além de 
um compromisso internacionalmente assumido, um imperativo constitucional. Afinal, os objetivos previstos no artigo $3^{\circ} \mathrm{da} \mathrm{CF} / 88$, de que são exemplos a erradicação da pobreza e da marginalização e a redução de desigualdades sociais e regionais, só poderão ser atingidos se os poderes públicos levarem em conta a diminuição das desigualdades desde os pontos de partida. Em outras palavras, não adianta esperar os resultados da implementação de uma política pública se as condições para fruição dos direitos que ela vem garantir não forem oferecidas.

A concretização das políticas públicas é tarefa complexa, que demanda a intervenção racional do Estado, em um conjunto de ações que envolvem, além da escolha de prioridades, a implementação de medidas legislativas, administrativas e financeiras. $\mathrm{O}$ processo de elaboração de uma política pública deve ser equacionado, pois, levando-se em conta os ditames constitucionais, os compromissos assumidos internacionalmente e os espaços deixados à discricionariedade do administrador, envolvendo diferentes etapas: planejamento, fixação de objetivos, escolha dos meios adequados, definição dos métodos de ação e destinação de recursos.

Ocorre que, diferentemente de outros institutos jurídicos, as políticas públicas não se encaixam em categorias tradicionais do direito, pois não constituem um ato isolado (como um contrato, por exemplo), mas podem ser decompostas numa série de atos de natureza heterogênea (Lopes, 1998, p. 131-132). Não é por acaso que se diz que a expressão jurídica de uma política pública pode assumir diferentes formas: leis, atos administrativos, decretos etc. (Bucci, 2002, p. 257 e ss). A peculiaridade desse conjunto de atos é o fato de estarem unidos por um objetivo comum, delineando um programa a ser executado em longo prazo (Comparato, 1999, p. 306).

No caso da educação, a Emenda Constitucional n. 14/96, ao criar o Fundo de Manutenção e Desenvolvimento do Ensino Fundamental (FUNDEF), cristalizou um aspecto importante da política de ensino fundamental brasileira, estabelecendo critérios e prioridades de ação e financiamento, focados no atendimento ao ensino fundamental obrigatório e gratuito (então de 7 a 14 anos), excluindo a educação infantil (subdividida em creche e pré-escola), o ensino médio e a educação de jovens e adultos (modalidade de ensino voltada àqueles que não cursaram o ensino fundamental e médio na chamada "idade esperada"). 
Já a Emenda n. 53/06, ao instituir o Fundo de Manutenção e Desenvolvimento da Educação Básica e de Valorização dos Profissionais da Educação (FUNDEB), representou um avanço em termos da implementação progressiva do direito à educação, pois incluiu o atendimento à educação infantil e ao ensino médio entre suas metas. Com essa mudança, prevê-se que a política de financiamento educacional brasileira ampliará o seu alcance, passando de 30,2 para 48,1 milhões de alunos a partir do quarto ano de vigência do respectivo Fundo (conforme dados do Censo Escolar de 2005). O montante de recursos, conforme a escala de implantação gradual do Fundo, prevista pelo governo federal, também terá um aumento significativo.

Um aspecto que gostaríamos de ressaltar - dado o seu caráter inovador e democrático - é a ampliação dos canais de participação da sociedade civil na elaboração, fiscalização e controle de políticas públicas, por meio da criação de conselhos de direitos, também chamados conselhos de políticas públicas ou conselhos gestores de políticas setoriais nas áreas de saúde, assistência social, educação e direitos da criança e do adolescente. Os conselhos, inseridos na esfera pública por força de lei, são órgãos colegiados, permanentes e constituem espaço de mediação entre o governo e a população. São diversos formatos de composição e funcionamento, mas o importante é a garantia da participação social na tomada de decisões política (Gohn, 2000, p. 38).

$\mathrm{Na}$ área da educação, as formas colegiadas de participação abrangem, ainda, o Conselho Nacional e os conselhos estaduais e municipais de Educação. O Conselho Nacional de Educação, na sua versão atual, foi criado sob a égide da Nova Lei de Diretrizes e Bases e - diferentemente dos conselhos gestores de políticas públicas - tem caráter centralizador. Os conselhos estaduais e municipais quase sempre reproduzem a forma do Conselho Nacional. Realizam a adaptação das leis nacionais para a respectiva esfera de atuação e criam suas próprias decisões (Boaventura, 1994, p. 225-226).

Entretanto, talvez os conselhos participativos na área da infância sejam os que representam maior potencial de formulação, implementação e controle efetivamente social de políticas públicas, com envolvimento de agentes ligados ao cotidiano de crianças e adolescentes. Há o Conselho Nacional da Criança e do Adolescente (CONANDA), órgão deliberativo, ligado ao Ministério da Justiça, encarregado da formulação 
de políticas para a infância no Brasil; os conselhos estaduais e municipais de Direitos da Criança e do Adolescente e o Conselho Tutelar (este de âmbito municipal).

A criação desses órgãos não deve ser vista de forma isolada. Ela reflete um longo processo de transformação no que se refere ao tratamento dispensado à infância e à adolescência, resultado de um consenso produzido internacionalmente. Nesta matéria, destaca-se o disposto no artigo $227 \mathrm{da}$ CF/88, em que se encontra sintetizada a Doutrina Jurídica da Proteção Integral à Infância, das Naçōes Unidas. O caput do referido diploma legal estabelece o dever da família, da sociedade e do Estado de assegurar à criança e ao adolescente, com absoluta prioridade, o direito à vida, à saúde, à alimentação, à educação, ao lazer, à dignidade, entre outros (grifo nosso). Já o $\$ 7^{\circ}$ estabelece que, na área da assistência social, o atendimento dos direitos da criança e do adolescente levará em conta os princípios da descentralização político-administrativa e da participação popular, no que se refere à formulação de políticas e ao controle das ações em todos os níveis (cf. art. 204, I e II da $\mathrm{CF} / 88$ ). Estas orientaçōes foram reafirmadas no Estatuto da Criança e do Adolescente (ECA), Lei n. 8.069/90, que, em seu artigo 88, inciso III, acolheu os mesmos princípios previstos no artigo $204 \mathrm{da}$ CF $/ 88$.

Destacamos o caso das crianças e adolescentes como categorias que merecem proteção reforçada. Contudo, há outros grupos, como os portadores de necessidades especiais (CF/88, art. 208, III) e os índios $\left(\mathrm{CF} / 88\right.$, art. $\left.210, \$ 2^{\circ}\right)$, que também são alvo de um tratamento jurídico diferenciado.

Um outro aspecto que deve ser levado em conta em termos de políticas públicas educacionais é a priorização das áreas mais desfavorecidas do país, com o intuito de reduzir as desigualdades regionais. As mazelas da educação brasileira (analfabetismo, repetência, evasão escolar, formação inadequada de professores) agravam-se ainda mais quando se trata da educação rural, "onde se somam classes multi-seriadas (várias séries em uma única classe), professores leigos, as grandes distâncias sem transporte e a mobilidade das famílias" (Silva, 1998). Neste caso, a necessidade de políticas públicas é mais do que urgente.

Nas áreas rurais do país ou, ainda, nas periferias dos grandes centros urbanos, é comum encontrar alunos com inúmeras dificuldades para chegarem à escola. Além das políticas para implementação de serviços 
públicos de ensino e para a melhoria da qualidade de ensino dos serviços já existentes nestas regiōes, cabe ao poder público garantir a oferta de transporte escolar. No caso de ausência ou insuficiência de vagas numa escola pública próxima à residência do interessado, ou no caso de simplesmente não existir nenhuma escola nas proximidades, o poder público deve fornecer, gratuitamente, o transporte para a escola mais próxima para que possa cumprir sua obrigação. Se isso não for possível, pelo fato de a escola situar-se em local muito distante, é obrigação do poder público garantir a vaga e o pagamento das mensalidades numa entidade privada. Vale ressaltar, ainda, que o Estatuto da Criança e do Adolescente assegura o acesso à escola pública e gratuita próxima da residência do educando (art. 53, v).

\section{Conclusão}

Após este breve panorama a respeito dos parâmetros que devem informar a tarefa de concretização do direito educacional, é possível afirmar que o Estado deve aparelhar-se para fornecer a todos, progressivamente, os serviços educacionais mínimos. Isso significa reconhecer que o direito à educação só se efetiva mediante o planejamento e a implementação de políticas públicas. Em outras palavras, a satisfação do direito não se esgota na realização do seu aspecto meramente individual (garantia de uma vaga na escola, por exemplo), mas abrange a realização de prestações positivas de natureza diversa por parte do poder público, num processo que se sucede no tempo.

Em síntese, a educação, como direito fundamental de caráter social: a) ocupa posição de destaque no ordenamento jurídico, servindo mesmo como razão de ser de toda a ordem jurídica, juntamente com os demais direitos fundamentais; b) tem aplicabilidade imediata, embora sua realização integral só possa se dar de forma progressiva; c) não pode ser suprimida do ordenamento jurídico por meio de emenda constitucional; d) pertence a todos, mas deve priorizar categorias de pessoas que se encontram numa mesma posição de carência ou vulnerabilidade; e) tem como sujeito passivo o Estado; f) realiza-se por meio de políticas públicas ou programas de ação governamental; g) vincula a todos os poderes públicos (Executivo, Legislativo e Judiciário), que devem adotar medidas - legislativas, técnicas e financeiras até o máximo dos recursos disponíveis, para a satisfação daquilo que 


\section{foi eleito como prioritário (núcleo mínimo obrigatório), reconhecendo o direito à educação como um verdadeiro direito.}

\section{Recebido em julho de 2007 e aprovado em agosto de 2007.}

\section{Notas}

1. "A vinculação é a expressão legal da prioridade estratégica que se atribui à educação, quando se pensa num projeto de desenvolvimento econômico e de construção da cidadania, numa perspectiva de universalização do saber, da cultura e da riqueza social" (Oliveira, 1998, p. 127-8).

2. "A importância da educação para o processo de construção da democracia sempre foi muito enfatizada, mas não necessariamente efetivada. Isso implica, de um lado, a presença de um ordenamento jurídico como a LDB, capaz de encaminhar os processos educacionais para os princípios e fins da educação nacional (art. 206), com base nos fundamentos democrático-republicanos $\left(\operatorname{art.} 1^{\circ}\right)$. Mas, de outro lado, a recorrente assinalação de metas universalistas, não efetivadas com a proclamação reiterada do direito à educação escolar obrigatória e gratuita do ensino fundamental e apoiada na vinculação orçamentária, evidencia o quanto de dívida social se tem a resgatar, em função do regime escravocrata vigente no país até 1988, e dos regimes socialmente excludentes que lhe seguiram” (Cury, 2000, p. 583). Neste sentido, os novos parâmetros instituídos pelo Estado social de direito representam um forte avanço, mas precisam sair do plano da mera declaração para o da concreta efetivação.

3. Dermeval Saviani, ao comentar a importância de se instituir um verdadeiro sistema nacional de educação no Brasil, abrangente e universalizado, reforça o objetivo de "formar seres humanos plenamente desenvolvidos e, pois, em condição de assumir a direção da sociedade ou de controlar quem a dirige" (Saviani, 1998, p. 210). No dizer de Anísio Teixeira, "a democracia não pode existir sem educação para todos e cada um, pois importa em transformar, não alguns homens, mas todos os homens para - contra tendências hereditárias, sociais, se não biológicas - rematar, por evolução consciente, a obra que as sucessivas civilizaçôes, desde o começo dos séculos, vêm realizando pela injustiça e conseqüente violência. Todas as outras formas de sociedade precisam de alguma educação, mas só a democracia precisa de educação para todos e na maior quantidade possível" (Teixeira, 1969, p. 220).

4. O sociólogo T. H. Marshall, em seu clássico artigo "Cidadania, classe social e status", afirma: "o direito à educação é um direito social de cidadania genuíno porque o objetivo da educação durante a infância é moldar o adulto em perspectiva. Basicamente, deveria ser considerado não como o direito da criança freqüentar a escola, mas como o direito do cidadão adulto ter sido educado" (Marshall, 1967, p. 73). Assim, os jovens e adultos que não cursaram o ensino fundamental na chamada idade esperada deveriam ser considerados alvos prioritários das políticas públicas educacionais. O Estado tem uma dívida social para com esse grupo extremamente vulnerável, privado de um direito social básico, razão pela qual a oferta do ensino fundamental na modalidade suplência não poderia jamais ser considerada uma mera faculdade do poder público.

5. O princípio da gratuidade da educação está previsto na legislação brasileira desde a Constituição Imperial de 1824, embora fosse reservado, àquela época, exclusivamente

Educ. Soc., Campinas, vol. 28, n. 100 - Especial, p. 691-713, out. 2007

Disponível em <http://www.cedes.unicamp.br> 
aos considerados cidadãos. Já a Constituição de 1891 “cala-se sobre o assunto, pois, radicalizando a autonomia dos estados, deixava essa 'faculdade' às constituições dos mesmos (...). Após 1891, muitos estados assumiram a gratuidade, mas boa parte deles repassou essa incumbência aos Municípios, pobres em arrecadação de impostos (...). A gratuidade nasceu em 1824 e morreu em 1891, em termos nacionais. A sua ressurreição em 1934 já vem associada com a obrigatoriedade, ambas em âmbito nacional, valendo para o ensino primário, isto é, para os quatro primeiros anos (...) gratuidade e obrigatoriedade seguem juntas e continuam como tais quando, em 1967, a Constituição Federal as estende para oito anos. Curioso aspecto: aumenta-se o tempo da escolaridade e retira-se a vinculação constitucional de recursos [estabelecida na Constituição de 1934] com a justificativa de maior flexibilidade orçamentária (...). A Constituição Federal de 1988 determinará a gratuidade em todo ensino público, em qualquer dos seus níveis e em qualquer parte do território federativo. Em nível nacional, a gratuidade, até então, só tinha vigência para o ensino dos oito anos obrigatórios. A gratuidade passa a valer também para o ensino médio e superior, quando oferecidos pelos poderes públicos" (Cury, 2000, p. 572-576).

6. Na Constituição de 1988, o princípio da solidariedade vem afirmado no artigo $3^{\circ}$ - I e III - como objetivo fundamental de nossa organização política interna; no artigo $4^{\mathrm{o}}$, IX, como diretriz de nossa política exterior; no artigo 170, como ditame de justiça social, na organização da ordem econômica; e no artigo 193, pela indicaçăo do bem-estar e da justiça social como base da ordem social.

\section{Referências bibliográficas}

BOAVENTURA, E.M. União, estados, municípios e os sistemas de educação. Revista de Informação Legislativa, Brasília, DF, v. 31, n. 122, abr./jun. 1994.

BONAVIDES, P. Curso de direito constitucional. 10. ed. São Paulo: Malheiros, 2000.

BOSI, A. A educação e a cultura nas constituições brasileiras. In: BosI, A. (Org.). Cultura brasileira: temas e situaçôes. 2. ed. São Paulo: Ática, 1992.

BUCCI, M.P.D. Direito administrativo e políticas públicas. São Paulo: Saraiva, 2002.

CANOTILHO, J.J.G. Direito constitucional e teoria da Constituição. 3. ed. Coimbra: Almedina, 1999.

COMPARATO, F.K. Ensaios sobre o juízo de constitucionalidade de políticas públicas. In: Mello, C.A.B. (Org.). Direito administrativo e constitucional: estudos em homenagem a Geraldo Ataliba. São Paulo: Malheiros, 1997. v. 2. 
COMPARATO, F.K. A afirmação histórica dos direitos humanos. São Paulo: Saraiva, 1999.

CURY, C.R.J. A educação como desafio na ordem jurídica. In: LOPES, E.M.T. 500 anos de educação no Brasil. Belo Horizonte: Autêntica, 2000. p. $567-584$

GOHN, M.G. Os conselhos de educação e a reforma do Estado. In: Carvalho, M.C.A.A.; TeiXeira, A.C.C. (Org.). Conselhos gestores de políticas públicas. São Paulo: Pólis, 2000.

JAEGER, W.W. Paidéia: a formação do homem grego. São Paulo: Martins Fontes, 1989.

LOPES, J.R.L. Direitos subjetivos e direitos sociais: o dilema do Judiciário no Estado social de direito. In: Faria, J.E. (Org.). Direitos humanos, direitos sociais e justiça. São Paulo: Malheiros, 1998.

MARSHALL, T.H. Cidadania e classe social. In: Marshall, T.H. Cidadania, classe social e status. Rio de Janeiro: Zahar, 1967.

OLIVEIRA, R.P. O financiamento público da educação e seus problemas. In: Oliveira, R.P. (Org.). Política educacional: impasses e alternativas. São Paulo: Cortez, 1998.

PIOVESAN, F.C. Direitos humanos e o direito constitucional internacional. 4. ed. São Paulo: Max Limonad, 2000.

SAVIANI, D. A nova lei da educação - LDB: trajetória, limites e perspectivas. Campinas: Autores Associados, 1998.

SILVA, A.M. Educação rural. In: Silva, E.B. (Org.). A educação básica pós-LDB. São Paulo: Pioneira, 1998.

STEINER, H.; ALSTON, P. International human rights in context: law, politics and morals. New York: Oxford University, 1996.

TEIXEIRA, A.S. Educação e o mundo moderno. São Paulo: Nacional, 1969.

TRINDADE, A.A.C. Tratado de direito internacional dos direitos humanos. Porto Alegre: Fabris, 1999. v. 1.

VERAS, M.E.B.; MARTINS, R.C.R. O financiamento da educação pública no Brasil. In: ENCONTROS pela Justiça na Educação. Brasília, DF: MEC; FUNDESCOLA, 2000. 